\title{
Coartación de aorta: causa de hipertensión arterial poco reconocida en el primer nivel de atención
}

\section{Coarctation of the aorta:cause of low-recognized high blood pressure at the first level of care}

\author{
Jhonattan J.Villena-Prado ' $y$ \\ Dayana Y. Castillo-Roque '
}

\author{
Villena-Prado J], Castillo-Roque DY. Coartación de aorta: causa de \\ hipertensión arterial poco reconocida en el primer nivel de atención. \\ Rev Soc Peru Med Interna. 2020;33(I):44-46. \\ https://doi.org/10.36393/spmi.v33i1.511
}

\begin{abstract}
RESUMEN
La coartación de aorta es una causa poco frecuente de hipertensión arterial secundaria, asimismo representa aproximadamente el $5-10 \%$ de las cardiopatías congénitas. El presente reporte relata el caso de una mujer de 42 años, con hipertensión arterial refractaria, quien recibió un diagnóstico y manejo inadecuado en el primer nivel de atención. Finalmente, se le diagnosticó una coartación de aorta. Se resalta la importancia de una anamnesis detallada y el examen clínico en la práctica médica rutinaria y una buena anamnesis como herramienta principal de todo acto médico, así como la derivación oportuna a la especialidad correspondiente para su manejo.
\end{abstract}

Palabras clave: hipertensión arterial, coartación aórtica, atención primaria.

\section{ABSTRACT}

Aorta coarctation is a rare cause of secondary high blood pressure, and also accounts for approximately 5 - $10 \%$ of congenital heart disease. This report relates the case of a 42 -year-old woman, with a history of refractory high blood pressure, who received an inadequate diagnosis and management at the first level of care. Eventually, she was diagnosed with a coarctation of the aorta. It highlights the importance of detailed anamnesis and clinical examination in routine medical practice and good anamnesis as the main tool of any medical act, as well as the timely referral to the corresponding specialty for its management.

Keywords: high blood pressure, coarctation aortic, primary care.

Médico-cirujano. Centro de Salud de Chungui, provincia de La Mar, Ayacucho.

\section{INTRODUCCIÓN}

La coartación de aorta es una patología con una frecuencia, aproximadamente, de 5\% del total de patologías congénitas a nivel mundial. ${ }^{1}$ Es de dos a cinco veces más frecuente en varones que en mujeres, y la edad típica de diagnóstico es entre los veinte y treinta años. ${ }^{2}$

Consiste en una deformidad de la pared media de la arteria aorta manifestada por un pliegue que estrecha de forma concéntrica la pared aórtica; asimismo, se asociarse a otras patologías, entre las más características válvula aórtica bicúspide, aneurismas, riñón poliquístico y síndrome de Turner. ${ }^{3,4}$

Al examen físico resalta la hipertensión en la mitad superior del cuerpo, disociación entre el pulso carotideo y femoral, y un soplo telesistólico en el borde esternal izquierdo que se irradia a la zona interescapular. ${ }^{4}$

El primer examen a realizarse deber ser una ecocardiografía, la cual permite visualizar el segmento de la coartación, las posibles lesiones asociadas y determina el grado de 
gradiente de presión a nivel de la coartación. ${ }^{3}$ El examen diagnóstico no invasivo es la angiotomografía y el invasivo es el cateterismo cardiaco convencional. ${ }^{5}$ Otro examen de imagen que va ganando terreno actualmente es la angiorresonancia magnética, con la ventaja de no usar radiación.

El tratamiento quirúrgico es la elección, realizándose una anastomosis termino-terminal.

\section{REPORTE DEL CASO}

Paciente mujer de 42 años, natural y procedente de Ayacucho, con antecedente de hipertensión arterial diagnosticada aproximadamente hace un año en un centro del primer nivel de atención, en Chungui (provincia de La Mar, Ayacucho, zona centro-sur del país, a $3500 \mathrm{msnm}$ ) en tratamiento farmacológico con un antihipertensivo y con antecedente de alergia al yodo.

La paciente vuelve a consulta hace seis meses por epistaxis intermitente y cefalea pulsátil. Se le consignó una PA de 160/90 mm Hg en el brazo izquierdo y se decidió agregar un segundo antihipertensivo y realizar una referencia. Esta no fue efectivizada porque la paciente no acudió por cuestiones laborales. Hace un mes, acudió nuevamente a control al Centro de Salud, y se le halló PA en ambos brazos de 150/70 mm Hg, un soplo sistólico en foco aórtico de intensidad II/VI y pulsos femorales y poplíteos $+1 /+3$, y se le añadió un tercer antihipertensivo (diurético), más una referencia a un hospital. Aquí, le solicitaron una AngioRM torácica y abdominal para descartar coartación de aorta (Figuras 1 y 2). Actualmente, la paciente es tratada en los servicios de cardiología y cirugía cardiovascular en un hospital de tercer nivel para manejo y tratamiento quirúrgico.

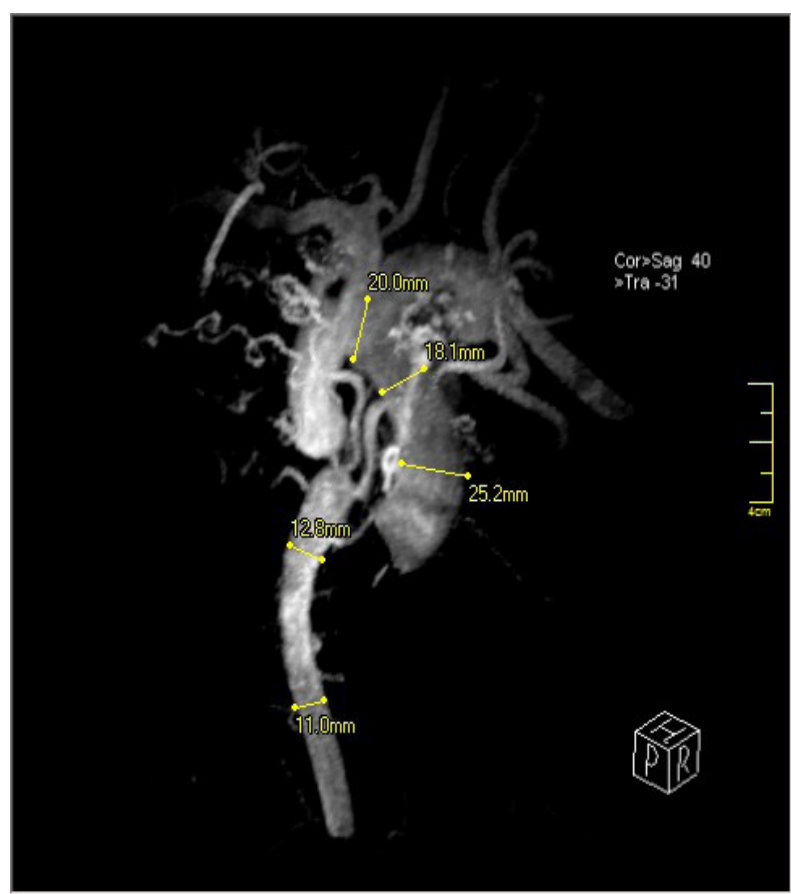

Figura 1. Imagen tomográfica. Coartación aórtica

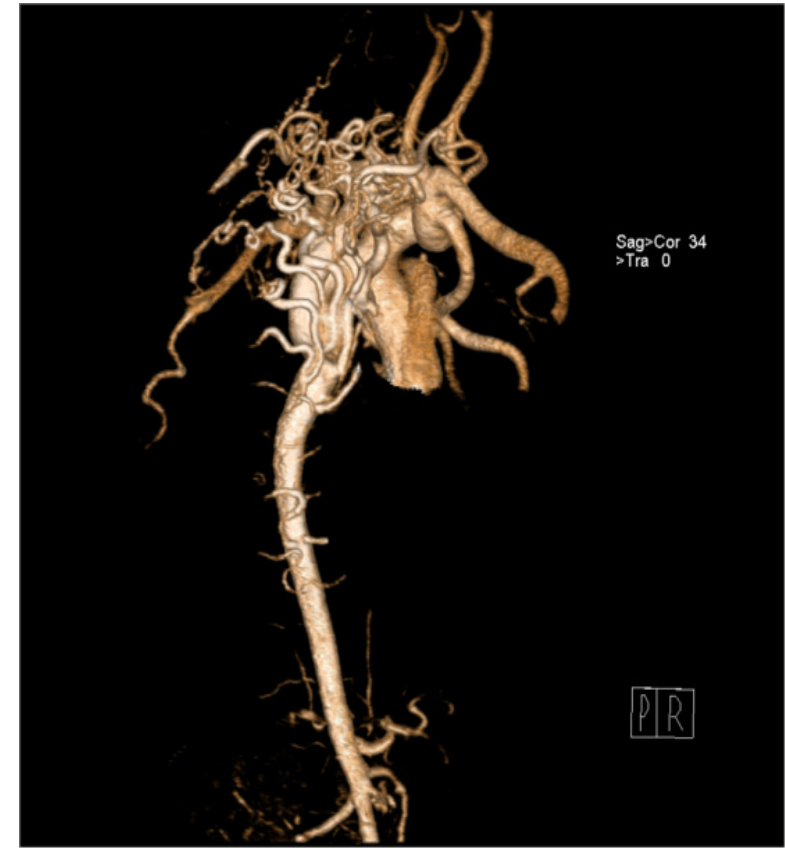

Figura 2. Reconstrucción digital. Coartación de aorta y múltiples ramas colaterales.

\section{DISCUSIÓN}

La importancia de este caso radica en cuanto al diagnóstico y manejo médico que recibió la paciente desde un año atrás, ya que generalmente se asume en la práctica médica el diagnóstico de hipertensión arterial primaria sin ahondar en el descarte de las causas secundarias; sin embargo, es igual de importante enfatizar que, por cuestiones laborales propias de las zonas andinas de nuestro país, hubo una demora por parte de la paciente para efectivizar la referencias a un centro de mayor complejidad.

La coartación de aorta ha sido ampliamente estudiada, pero la falta de una anamnesis minuciosa (episodios de epistaxis, claudicación, etc.) y el no realizar un examen clínico completo, como palpar los pulsos y medir la presión arterial en las extremidades superiores e inferiores, sigue siendo la causa principal de que esta patología sea poco diagnosticada.

Generalmente, la presentación habitual de la coartación de aorta en la edad adulta es debida a hipertensión o sus complicaciones; dentro de las cuales, se describe la dilatación aórtica (el diámetro normal de la aorta ascendente definido como $<2,1 \mathrm{~cm} / \mathrm{m}^{2}$; y, diámetro normal de la aorta descendente como $<1,6 \mathrm{~cm} / \mathrm{m}^{2}$.), lo que puede llevar a patología aórtica (aneurismas, disecciones y rupturas) que puede ser una de las principales causas de muerte en este tipo de pacientes. ${ }^{6,7}$

Finalmente, se debe enfatizar en este caso en lo que debió ser una derivación oportuna a la especialidad o especialidades correspondientes para el manejo médico/ quirúrgico adecuado y evitar así las complicaciones propias de la enfermedad, con demoras tanto en realizar un diagnóstico acertado como propias del paciente al priorizar otras actividades. 
En conclusión, es importante el descarte inicial de las causas secundarias de hipertensión arterial mediante una anamnesis detallada y un examen clínico minucioso, lo que consecuentemente se traduce en un diagnóstico adecuado de enfermedades, inclusive poco frecuentes, como la coartación de aorta.

El diagnóstico y la derivación precoz desde el primer nivel de atención (primer contacto médico) permiten reducir la aparición de complicaciones producto de la enfermedad y brindar un tratamiento médico/quirúrgico oportuno.

\section{REFERENCIAS BIBLIOGRÁFICAS}

I. Tanous D, Benson LN, Horlick EM. Coarctation of the aorta: evaluation and management. Curr Opin Cardiol. 2009; 24:509-15.

2. Brickner ME, Hillis LD, Lange RA. Congenital heart disease in adults. N Engl J Med. 2000; 27; 342 (4): 256-63.
3. Zhao Q, Shi K, Yang ZG, Diao KY, Xu HY, Liu X, Guo YK. Predictor of aortic dilatation in patients with coarctation of the aorta: evaluation with dual source computed tomography. BMC Cardiovasc Disord. 2018;18(I):124.

4. Navarro-López F. Cardiopatías Congénitas. Farreras-Rozman. Tratado de medicina interna ( $18^{\mathrm{a}}$ ed.). Madrid, Elsevier, 2016; 597 8.

5. Ruíz P, Méndez D. Coartación de aorta: una revisión sistemática Ciencia e Innovación en Salud. 20I5; 3 (2): 31 - 42.

6. Vásquez R, Pastor M, Calvo J, Rodríguez M, Front C, Cubero J, et al. Coartación de aorta: diferentes formas anatomo-clínicas según la edad de presentación. Revista Española de Cardiología. 1998, 5I(7).572-585.

7. Raimund Erbel, Holger Eggebrecht. Aortic dimensions and the risk of dissection. Heart. 2006;92:137-142.

\section{CORRESPONDENCIA:}

Correo electrónico:Jhonv1807@gmail.com

FECHA DE RECEPCIÓN: 05-05-2020.

FECHA DE ACEPTACIÓN: 09-03-2020. 